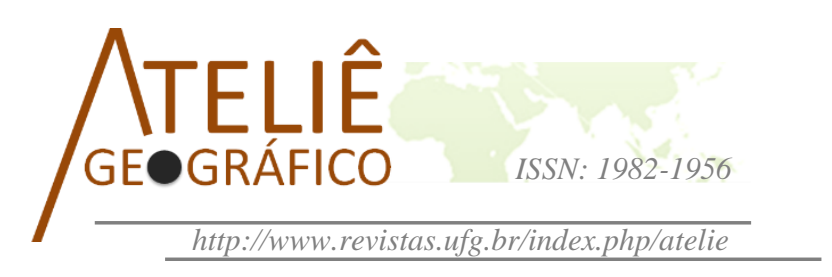

\title{
Impactos da acumulação com predominância financeira sobre a nova Geografia industrial-processos produtivos, competitividade e diferenciação espacial
}

\author{
Impacts of accumulation with financial predominance on the \\ new industrial Geography - productive processes, \\ competitiveness and spatial differentiation
}

\section{Impacts de l'accumulation avec prédominance financière sur la nouvelle Géographie industrielle - processus de production, compétitivité et différenciation de l'espace}

\author{
Edilson Pereira Júnior \\ Universidade Estadual do Ceará (UECE) \\ edilsonapjr@hotmail.com
}

\begin{abstract}
Resumo
$\mathrm{O}$ artigo examina as consequências da acumulação com predominância financeira sobre a organização do mundo industrial, ao considerar o conjunto de mudanças dos processos produtivos como um desdobramento importante das alterações consolidadas pelas configurações capitalistas contemporâneas. São trabalhadas as formas segundo as quais o imperativo da acumulação pela via financeira submete as empresas industriais à sua lógica competitiva, exigindo delas desempenhos de produtividade que superem os padrões anteriormente estabelecidos pela configuração do tipo fordista. A intensão é investigar as novas Geografias dessas transformações, cujo resultado é a constituição de uma relação articulada de territórios unidos por uma divisão do trabalho turbulenta e dinâmica, num arranjo contraditório de diferentes margens espaciais de lucratividade.
\end{abstract}

Palavras-chave: Financeirização; Indústria; Diferenciação espacial.

\begin{abstract}
This article analyses the consequences of accumulation with financial predominance on the organization of the industrial world considering the set of changes on the productive processes as an important development of the consolidated changes by the contemporary capitalist configurations. We work out the ways in which the financial accumulation imperative subordinates industrial enterprises to their competitive logic, requiring productivity performances that surpass the patterns previously established by the Fordist configuration. The intention is to investigate the new geographies of these
\end{abstract}


transformations whose result is the constitution of an articulated relationship of territories united by a turbulent and dynamic division of labor, in a contradictory arrangement of different spatial margins of profitability.

Keywords: Financialization; Industry; Spatial differentiation.

\begin{abstract}
Résumé
L'article examine les conséquences de l'accumulation avec la prédominance financière sur l'organisation du monde industriel, en considérant l'ensemble des changements des processus de production comme un déroulement important des changements consolidés par les configurations capitalistes contemporaines. Le but est de travailler les façons à laquelle le l'impératif d'accumulation par des moyens financiers soumet les entreprises industrielles à leur logique concurrentielle, en leur exigeant gains de productivité qui dépassant les normes précédemment établies par la configuration de type fordiste. L'intention est d'enquêter sur les nouvelles Géographies de ces transformations, qui aboutissent à la constitution d'une relation articulée de territoires unis par une division turbulente et dynamique du travail, dans un arrangement contradictoire de différentes marges de l'espace de de rentabilité.

Mots-clés: Finance; L'Industrie; Différenciation de l'Espace.
\end{abstract}

\title{
Introdução
}

Em tempos de acumulação capitalista com forte predominância da instância financeira como mecanismo de fluidez dos movimentos e de subordinação dos territórios, como fica a organização do mundo industrial e sua resultante espacial?

Este texto procura realizar uma discussão acerca do tema, sobretudo ao considerar o conjunto de mudanças dos processos produtivos como um desdobramento importante das transformações consolidadas pela reestruturação territorial sentida pela indústria, num contexto de modificações das configurações capitalistas contemporâneas.

Nas últimas décadas, em escala mundial, a indústria está muito mais propensa a absorver uma nova combinação entre relações espaciais, produtivas, financeiras e de serviços, capaz de revelar mecanismos complexos de organização dos sistemas industriais. Por meio dessas novas relações, que reconfiguram os termos da economia produtiva e da circulação/consumo de bens e mercadorias; e devido à nova capacidade de relocalização das atividades produtivas, um novo conjunto de elementos consolida diferentes concepções gerenciais e territoriais de produção industrial, aproximando as performances das linhas de produção fabril à gestão financeira. Esta, por sua vez, pressiona o funcionamento da indústria como um todo e a ordem mais premente é garantir a maximização dos lucros ou de rentabilidades, em especial ao aproveitar as tecnologias de informação capazes de transformar flexibilidade em novas estratégias de controle sobre o trabalho e o espaço.

O artigo realiza essas discussões a partir de uma revisão de literatura que articulam as mudanças nas estratégias produtivas com a capacidade cada vez maior de mobilidade dos investimentos e de dispersão da apropriação das lucratividades pelo desenvolvimento espacial desigual. Trata-se de uma maneira de compreender o controle 
das forças hegemônicas contemporâneas de acumulação (MÉNDEZ, 2018; BRENNER, 2018; PECK, THEODORE e BRENNER, 2012).

Primeiramente, são trabalhadas as formas segundo as quais o imperativo da acumulação pela via financeira submete as empresas industriais e comerciais à sua lógica competitiva, exigindo delas desempenhos de produtividade e de lucratividade que superem os padrões anteriormente estabelecidos pela configuração do tipo fordista. É enfatizada a dinâmica que estimula a dimensão financeira a ultrapassar os seus próprios limites, se estendendo às outras dimensões da economia, isto é, às da produção e das trocas.

O item seguinte versa sobre o alcance e a espacialidade dessas transformações, cujo resultado é a constituição de um conjunto relacional e articulado de territórios unidos por uma divisão do trabalho turbulenta e dinâmica, num arranjo contraditório de diferentes margens espaciais de acumulação.

Por fim, as considerações procuram sintetizar as ideias principais levantadas, assim como, buscam abrir a discussão para um renovado debate sobre o tema.

\section{Competitividade e formas de acumulação no novo mundo industrial}

Os acontecimentos manifestados em 2008 pela aguda crise financeira mundial não fizeram mais do que ampliar as intervenções estatais e a nacionalização de prejuízos de instituições financeiras e conglomerados produtivos multinacionais. Passados dez anos dos impactos propagados pela crise hipotecária dos Estados Unidos e pelo colapso de economias inteiras, como Islândia e Grécia, os fluxos financeiros, as formas de governança e as proteções políticas a um certo tipo de acumulação pautado na financeirização das riquezas somente se ampliaram (MÉNDEZ, 2018; BRENNER, 2018; SASSEN, 2016; PECK, THEODORE e BRENNER, 2012).

Isso confirma a tese de Peck, Theodore e Brenner (2012), segundo a qual, apesar de parecer uma estrutura monolítica hegemônica e ostensivamente global no alcance, a configuração capitalista pautada no domínio das finanças, chamada pelos autores de neoliberalismo, se associa a um conjunto quase desconcertante de trajetórias regionais, formas contingentes e combinações híbridas. Ela não "existe como uma estrutura unificada e estática, como um sistema de equilíbrio ou como uma condição final", propensa a ser demolida numa situação de grande crise. Muito pelo contrário, se apresenta mais como um "ethos hegemônico de reestruturação, um padrão dominante de transformação regulatória”, operando "entre seus 'outros', em ambientes de governança múltipla, heterogênea e contraditória” (PECK, THEODORE e BRENNER, 2012, p. 61).

Pensar a acumulação pautada na financeirização das riquezas como uma estrutura monolítica, sem articulações ou porosidades entre contraditórios agentes políticos e econômicos, desse modo, não seria mais do que uma falsa ilusão. O mesmo ocorre com a concepção que vê autonomia do capital portador de juros na extração do valor como riqueza social (AUVRAY e RABINOVICH, 2018). Segundo esta leitura de mundo, as outras dimensões econômicas da vida tornaram-se desimportantes para as formas de 
acumulação, como se o capital portador de juros não fosse apenas uma forma funcional do capital e sua dinamização não estivesse associada à produção e à comercialização de mercadorias.

$\mathrm{Na}$ verdade, apesar do atual domínio da financeirização sobre outras frações de capital na economia de mercado, o que ocorre na maioria das vezes é a transferência de valor entre as formas funcionais de apropriação, tornando a lógica da produção material subordinada à especulação dos velhos e dos novos mecanismos financeiros (MÉNDEZ, 2018).

Harvey, não sem espanto e sem manifestar a natureza preliminar de suas conclusões, escreveu em 1989:

Estou, portanto, tentado a ver a flexibilidade conseguida na produção, nos mercados de trabalho e no consumo antes como um resultado da busca de soluções financeiras para as tendências de crise do capitalismo do que o contrário. Isso implicaria que o sistema financeiro alcançou um grau de autonomia diante da produção real sem precedentes na história do capitalismo, levando este último a uma era de riscos financeiros igualmente inéditos (HARVEY, 1998 [1989], p.181).

O espanto de Harvey não escondia a surpresa com relação à nova forma de acumulação, submetida a um movimento no qual o capital fictício, instável e marcado por estratégias especulativas parasitárias passou a ditar os ritmos da economia. Em meio a essa questão, outra preocupação ficava evidente: diante de uma possível bancarrota dos mercados financeiros em função da avidez dos investidores por lucros exorbitantes, o que sobraria da "economia real", estando ela dependente dos grandes agentes das finanças internacionais e de suas "aventuras espetaculares"?

Essa preocupação nos assola ainda hoje, sobretudo em momentos de expressivas instabilidades dos mercados financeiros. No entanto, muitas das dúvidas acerca da manutenção dessa configuração e da sua capacidade de extrair valor da "economia real" foram respondidas não só por meio de profundas transformações nas formas de pensar a competitividade capitalista, mas também pela capacidade de reorganizar a produção material e sua distribuição até os mercados consumidores.

A chave da mudança está na subordinação da empresa industrial e comercial ao que Petrella (1996) chama de "princípio da competitividade". Segundo o autor, a competitividade, sob a influência da teoria e da prática econômica da financeirização, possui um sentido de enfrentamento entre rivais, convertendo as atitudes das empresas em estratégias cujo único propósito é derrotar os concorrentes.

Numa configuração de acumulação em que os grandes investidores buscam cada vez mais rentabilidade no curto prazo e estão interessados nas facilidades da liquidez, retirando seus investimentos no momento que lhes convém, qualquer iniciativa empreendedora na produção industrial ou na circulação de produtos e serviços será 
contaminada pela filosofia do engajamento sob as condições de retorno seguro e imediato (AUVRAY e RABINOVICH, 2018).

Assim, o imperativo da competitividade, além de se impor como meio, coloca-se como fim das relações econômicas e socioespaciais, ao se converter no principal objetivo de empresários do comércio e da indústria, banqueiros e lideranças governamentais. Naturalmente, essa premissa não se limita ao universo de uma empresa, a setores industriais ou a países e regiões do mundo, implicando uma micro, meso e macro escala da competitividade. Trata-se de apresentar o comportamento competitivo como uma dimensão social e humana, o único e poderoso motor de ação, motivação e inovação. Nesse caso, a alusão aos termos associados à gestão consagra a ideologia da competitividade como um imperativo do curto prazo e uma hegemonia dos lucros e dos benefícios econômicos como ato que se resume à superação e à "aniquilação" dos competidores.

A meta mais importante a ser defendida numa concepção dessa natureza é adquirir força para derrotar os adversários. Está declarada, assim, a "guerra econômica sem quartel". O vencedor será revelado pela destreza ao estabelecer corretamente a sua visão, a sua missão, os seus valores, os seus objetivos e as suas estratégias, num esforço de "agressividade" cujo "fracasso" implica a exclusão do mercado e a "conquista" leva à superação e ao bem-estar individual e coletivo (PETRELLA, 1996).

Assim, a obsessão pela liquidez e a concorrência econômica que dela resulta denunciam o caráter predatório do paradigma do individualismo, que torna o indivíduo maximizador da utilidade numa argamassa do pensamento dominante. Isso transforma o mercado num servomecanismo capaz de conciliar os planos egoístas como meta para todos os agentes sociais.

Para Santos (1999), existe um problema maior. Como a ideia de competitividade ganhou um movimento de expansão rápido e eficaz, os seus valores assumiram feição de verdade axiomática, restando às empresas aceitarem essa direção como única tábua de salvação. Trata-se de uma concepção que comanda o mundo como um circuito automático e é incorporada pelas empresas das mais diversas esferas da economia, como se representasse a força irresistível de uma lei da natureza. Desse modo, o planeta inteiro tornou-se um campo onde se materializa esse tipo de concorrência.

Na concepção de Michalet (2003, p.32), trata-se de uma lógica que "ultrapassa os limites da dimensão financeira para se estender às outras dimensões reais da economia, isto é, às da produção e das trocas”. Estabelece-se, nesse sentido, uma articulação entre os capitais, que se inicia a partir do movimento das variáveis próprias do mercado financeiro (taxas de juros, taxas de câmbio e os novos produtos geradores de ganhos especulativos) e se amplia até os outros domínios (a compra de ações, o mercado de commodities, as aquisições/fusões), fazendo com que a gestão das empresas se oriente pela administração da carteira dos bancos de investimento.

Por consequência disso, os ativos industriais são assimilados aos ativos das finanças. Ademais, a necessidade de satisfazer as normas impostas pelos mercados 
procura reconciliar as formas de circulação e organização produtiva com o imperativo socialmente dominante do "tudo-mercadoria". Ao subordinar suas estratégias às práticas financeiras, as empresas produtivas conjugam sua atuação tradicional a atividades renovadas, deixando-se contaminar pela filosofia da acumulação exacerbada e acelerada, tida aqui como princípio da competitividade.

Do ponto de vista normativo, a modalidade de organização capitalista que permite essa convergência de interesses é a sociedade anônima, "cujo caráter coletivista se sobrepõe aos capitais dispersos e, ao mesmo tempo, reforça sua rivalidade" (BELUZZO, 2005, p.7). Com respaldo desse mecanismo jurídico, a finança consegue alojar as suas estratégias de acumulação no seio dos grupos industriais. Desse modo, proprietários acionistas puramente financeiros submetem os administradores industriais aos códigos criados pelo mercado bursátil, comprando suas ações e submetendo-as a uma avaliação/classificação que respeita uma demanda de rendimentos estáveis elevados (AUVRAY e RABINOVICH, 2018). Segundo Chesnais (2005), tornou-se comum os administradores dos fundos de pensão e de aplicação financeira cobrarem das empresas das quais são acionistas um nível de rendimento de $15 \%$ dos seus fundos próprios.

Aos administradores das empresas, cabe a tarefa de responder à realidade dessa exigência. Diante da possibilidade de os diversos acionistas se desfazerem das ações cujos rendimentos não os satisfaçam, os administradores das empresas se adaptam aos ritmos de acumulação desejados pelos investidores, moldando a empresa industrial ao formato financeiro e, com isso, impondo-lhe prioridades bem diferentes da administração produtiva das décadas anteriores.

$\mathrm{Na}$ verdade, tratando-se dos maiores grupos empresariais produtivos, foi necessário substituir a figura do administrador industrial tradicional pelo savoir-faire dos novos grupos de administração, que compreendem os segredos dos mercados e dos serviços financeiros.

Assim, o novo administrador industrial moldou-se à lógica competitiva das finanças e suas prioridades mudaram, na medida em que estão submetidos a grupos de investidores para os quais a tendência da Bolsa ganhou prioridade (AUVRAY e RABINOVICH, 2018). É interessante também perceber como as normas estabelecidas pela busca da lucratividade máxima ultrapassam as relações com as finanças e tomam forma no novo mundo industrial. Após uma "contaminação inicial" nutrida por grupos de investidores financeiros por meio de pressões sobre as empresas produtivas de sociedade aberta, o que se vê é a generalização do princípio da competitividade para todas as empresas. Diretamente articuladas em função de uma concorrência global, empresas industriais de todos os tipos e de todos os tamanhos absorvem o imperativo da competitividade, e as transformações produtivas não mais se resumem ao grande grupo industrial influenciado de modo direto pelos mercados financeiros. Consequentemente, os padrões produtivos mudam como um todo e a atividade industrial, reagindo por mimetismo, toma para si os valores, as metas e os ritmos da acumulação com dominação financeira. 
O novo paradigma do mundo industrial acirrou a concorrência entre as empresas na atração de mercados consumidores em escala global. No afã de conquistar mais compradores em diversas regiões do mundo, os gestores das indústrias aceleraram as inovações gerenciais e produtivas, na ânsia de superar os concorrentes e atingirem as melhores performances de produtividade e comercialização. Os administradores mais ousados passaram a ser louvados pelas estratégias de inovação, ao alcançar bons resultados em relação aos competidores.

Assim, reiteramos as afirmações acerca dos padrões de acumulação impostos pela dinâmica financeira recente e sua capacidade de exigir das indústrias ganhos e arrecadações na quantidade e na velocidade dos novos ritmos de mercado. Na busca de tais objetivos, não há outra opção senão redefinir as metas e as formas de produção, estimulando também o aumento do consumo de produtos dispensáveis. A configuração capitalista com predominância financeira cobrou das indústrias a redefinição das suas formas de acumulação por pura mimetização das práticas realizadas pelo capital especulativo. Os resultados disso foram a exacerbação da concorrência e a mudança tecnológica, que acompanharam a reengenharia da produção com toda sorte de reestruturações flexíveis presentes nos últimos anos.

\section{Reestruturação produtiva e diferenciação espacial}

Desde que os encadeamentos do circuito econômico foram reconfigurados, não há mais crescimento capitalista sem que os fluxos de valor transitem pela esfera financeira. Mas, da mesma forma, não é possível assegurar mais-valia financeira aos investidores da atual economia de mercado sem que esta não seja permanentemente "abastecida" por excedentes extraídos da esfera da produção e da circulação.

Pela cobrança dos acionistas ou por puro mimetismo imposto pelo acirramento da competitividade, as performances da gestão financeira, caracterizada pelo uso de mecanismos de desregulamentação e volatilidade, pressionam o funcionamento do mundo industrial como um todo. A ordem premente é garantir a maximização dos lucros, sobretudo ao aproveitar as tecnologias de informação e comunicação capazes de transformar flexibilidade em novas estratégias de produção e controle sobre o trabalho.

Em nome dessas mudanças, a partir da década de 1980, as produções em série e em larga escala passaram a ser substituídas por uma produção diferenciada, em escala menor, que requeria a criação de unidades de produção mais "enxutas", com uma organização mais flexível, incorrendo em aumento da especialização e em novos padrões de hierarquia no interior das empresas (MÉNDEZ e CARAVACA, 1996). As maiores transformações dessa produção flexível se deram de três formas:

1) a formação de economias de escopo, na qual ocorre uma especialização flexível da produção em lotes voltados para segmentos pequenos de mercado.

2) a estratégia de mudança técnica rápida, a partir da distribuição da produção por diferentes empresas. 
3) a organização de um sistema definido pelo consumo, em que a produção é pensada do fim para o começo, tendo em vista a diversidade da demanda e a adaptação às condições diferenciadas.

Desde então, a palavra mais usada para definir as mudanças no capitalismo industrial passou a ser flexibilidade. Cada vez mais, seria preciso estabelecer flexibilidade (HUMPHREY apud PEREIRA, 1998):

1) nas relações entre empresas, por meio de sistemas de subcontratação e redes capazes de unir grandes organizações, fornecedores, pequenas empresas e microempresas, além de trabalho temporário externo ou em domicílio.

2) na contratação de serviços, na qual os empregos diversos poderiam ser fornecidos por empresas terceiras, que administrariam serviços de limpeza, manutenção, cantinas e vigilância, entre outros, ou forneceriam mão de obra, conforme a necessidade.

3) nos salários, estabelecidos conforme a produtividade do trabalhador, do seu grupo de trabalho, da unidade de produção, da empresa ou até do desempenho da economia.

4) nos direitos trabalhistas, com o ajuste do número de trabalhadores ao nível de produção, por meio de maior facilidade de demissão, contratação de trabalhadores temporários, contratos com prazo fixo e trabalho autônomo.

5) nos horários de trabalho, com sistemas de horário variáveis, tais como turnos reduzidos, dispensas temporárias, horas extras, reelaboração das escalas de férias e diminuição da jornada de trabalho a compensar, entre outros.

6) na funcionalidade, com o aumento da variedade de trabalho exercida pelos trabalhadores, os quais poderiam ser deslocados de uma tarefa para outra ou, ainda, designados a novas funções ampliadas e agregadas ao serviço original.

Assim, as novas formas concretas de organização industrial respeitam o imperativo que reproduz os sistemas territoriais e produtivos do nouveau monde industriel (VELTZ, 2008). Elas são caracterizadas por uma tessitura renovada, que integra uma rede de relações estabelecidas em múltiplas escalas, geradora de fluxos materiais e imateriais diversos. Nesse contexto, as interações espaciais e a divisão interempresarial do trabalho tornam-se mais abrangentes. A fabricação na indústria tende a envolver diferentes empresas de produção e de serviços, materializando relações produtivas, financeiras e comerciais por meio da articulação de agentes em várias estratégias (MÉNDEZ, 2018).

A consequência disso é que etapas antes realizadas dentro de plantas industriais se dispersaram, principalmente mediante a contratação de prestadores de serviços externos. A leitura mais completa dessas transformações, porém, só é possível se considerada a dimensão do espaço geográfico. Sabemos que só é possível entender processos produtivos em sociedade, constituído pelo conjunto de características políticas, econômicas e ideológicas que lhe são característicos, dispostos sobre uma base natural mais ou menos modificada. Assim, o espaço recebe o plano de articulação 
multidimensional da realidade, mas ele próprio, igualmente, se impõe como uma força produtiva. Como informa Santos (1999), é uma materialidade que conduz e suporta as intencionalidades econômicas, políticas e ideológicas, isto é, se apresenta como um intermediário e um instrumento, um ambiente e uma mediação.

À toda e qualquer ação econômica ou política deve sempre ser incluído o minucioso redesenho técnico do espaço, materializado por meio de inúmeros objetos que facilitam os fluxos e a interconexão entre os lugares. Somente assim as decisões e os rumos que garantem concentração e dispersão de investimentos ganham racionalidade, tornando a eficiência produtiva uma realidade e a complementaridade do circuito produção/circulação/distribuição/consumo um dado concreto (SANTOS, 1999).

Ao analisar a evolução das estratégias empresariais no espaço, Camagni (1993) enxerga três lógicas bem definidas no que tange à configuração dos fatores de produção e consumo que influenciam a articulação espacial entre as muitas empresas que compõem o circuito de relações:

1) a primeira lógica está associada ao que o autor chama de "organização territorial", na qual a empresa articula-se numa área de mercado restrita, geralmente em torno de sua localização geográfica. $\mathrm{O}$ arranjo espacial das atividades econômicas é organizado seguindo um princípio de gravitação, no melhor estilo christalleriano, em que a fricção espacial, representada pelo custo do transporte ou outros fatores locacionais, produz diferenciação no alcance e na capacidade de instalação da empresa, implicando uma maior eficiência da organização local e uma dificuldade para a inserção, nesse mercado, de empresas fixadas em regiões distantes.

2) em contraponto a esse modelo tradicional, instala-se a segunda lógica, uma "lógica competitiva", na qual o alcance comercial e produtivo da empresa "não se reduz unicamente ao mercado local, pois os custos de transporte não representam mais um papel importante". Desse modo, "a empresa pode vender seus produtos por toda parte, tentando controlar não mais a área de mercado mais vasta, mas a parte mais ampla do mercado (mundial)" (CAMAGNI, 1993, p. 109). Nessa lógica, a competição se dá de maneira diferente, pela própria capacidade de ação das empresas em mercados distantes, fazendo que novas estratégias de concorrência sejam utilizadas, com destaque para mecanismos de publicidade e outros ligados à relação entre as diferentes formas de capital ou entre essas formas e o Estado. Num modelo dessa natureza, a "localização da empresa é, portanto, determinada por uma vasta série de especificidades geográficas e históricas, e não mais por uma única lógica, como a advinda dos modelos de equilíbrio de localização gerais" (CAMAGNI, 1993, p. 109).

3) a terceira e mais recente lógica de organização espacial das empresas incorpora o imperativo da nova configuração capitalista, na qual os mercados são o princípio exclusivo da regulação e a competitividade é uma questão de sobrevivência. Por meio das novas tecnologias da informação e das reestruturações flexíveis, o espaço da articulação produtiva e do consumo traduz tais transformações numa "lógica em rede". Para a empresa, a inovação tecnológica transforma-se em função crucial e a sua evolução passa 
a ser associada às metas de produtividade e lucratividade, ao reestruturar as relações intraempresariais, interempresariais e espaciais.

As ligações no espaço, antes limitadas a um alcance reduzido, tornam-se globais a partir de formas e agentes previamente selecionados. As empresas visam construir uma rede global de unidades de produção e consumo, cuja especialização resulta de uma arbitragem conduzida em escala mundial, com localizações múltiplas para obter ótima alocação dos investimentos. Além disso, é estabelecida uma maior integração internacional entre as bases financeiras, os centros de pesquisa e desenvolvimento e as unidades de produção e distribuição, o que favorece o arranjo de estruturas horizontais flexíveis no que diz respeito às empresas, mas intensifica as relações verticais e hierárquicas no que concerne ao espaço.

Nesse sentido, a materialização espacial do último arranjo faz-se muito mais complexa, exigindo a presença de nós de centralidades, articulados por vias materiais e imateriais com fluxos de alta rotatividade, expressos num circuito que engloba zonas, pontos, polos, distritos, parques, eixos, rotas e corredores interconectados a partir das novas hierarquizações da acumulação capitalista de cunho financeirizado.

Em geral, essa configuração produz uma tessitura na qual uma densa rede de relações se estabelece, garantindo fluxos formais ou informais, materiais ou imateriais, ao gerar largo alcance dos modelos racionalistas de produção e circulação no espaço. Também se traduz por uma intensa divisão do trabalho entre empresas especializadas na fabricação de componentes específicos ou produtos acabados, articulando controle financeiro, gerência empresarial, escritórios de desenho industrial, fabricantes de bens finais e todo um conjunto de micro, pequenas, médias e grandes empresas industriais ou de serviços especializadas em atender a demandas auxiliares, materializando as relações produtivas, financeiras e espaciais de interdependência.

Assim, a relação entre as diversas fases da produção industrial confirma também uma articulação entre diferentes territórios ou regiões, com o grau de proximidade entre eles variando em função da fluidez espacial, da demanda produtiva ou da capacidade tecnológica e informacional da rede empresarial estabelecida. Como sabemos que o alcance dessas redes não se limita às escalas locais, observamos que a reestruturação espacial produz articulação internacional muito mais aberta e interdependente, submetendo o espaço a tensões mais profundas, com as relações entre agentes globais, nacionais e locais tornando-se mais complexas. Desse modo, de acordo com a intencionalidade dos agentes em destaque, os fluxos materiais e imateriais diminuem ou se ampliam, e o resultado disso é a inter-relação dinâmica entre espaços distantes e/ou a parca relação entre espaços vizinhos.

É uma configuração marcada pela subversão do sistema tradicional hierarquizado das polaridades, ao imputar uma requalificação da ideia de proximidade. De fato, à ideia tradicional de proximidade - definida pela intensidade dos fluxos de transportes, pessoas, produtos e mercadorias - deve ser acrescentada agora a noção de proximidade relativa, configurada a partir da maior densidade na circulação de informação (LENCIONI, 2006). 
É claro que a fluidez informacional não é possível sem uma regulamentação institucional, bem como a montagem de uma infraestrutura ou de uma logística eficiente no espaço. Para que as intencionalidades dos agentes na nova configuração capitalista se materializem, o território precisa responder positivamente, sobretudo no que diz respeito às intencionalidades convergentes dos agentes locais dominantes, geralmente traduzidas em ações políticas e econômicas que introduzem normas e sistemas de objetos adequados.

Assim, é na perspectiva transescalar que devem ser compreendidas as mudanças de estratégias de investimentos dos grandes grupos empresariais industriais e financeiros. Por conta da enorme capacidade de fluidez dos investimentos, ocorrem uma liberalização e uma desregulamentação das normas territoriais, num plano de integração aos grandes interesses hegemônicos. Trata-se de um fenômeno marcado pela seleção de territórios convenientes à reprodução ampliada das rentabilidades, concebido sob um sistema de operação de arbitragem com grande capacidade de decidir que lugar e quem serão beneficiados pelas virtudes dos investimentos.

Tal como Santos (1999), enfatizamos que [...] essa opulência de ações não se precipita de forma cega sobre qualquer ponto da Terra. As informações que constituem a base das ações são seletivas, buscando incidir sobre os lugares onde se possam tornar mais eficazes. Essa é uma lei implacável, num mundo sequioso de produtividade e onde o lucro é uma resposta ao exercício da produtividade (SANTOS, 1999, p.162).

No entanto, o espaço só se apresenta como mecanismo de acumulação capitalista em função da sua condição contraditória (homogênea e, ao mesmo tempo, fragmentada), que permite seu uso diferenciado por parte da sociedade. As qualidades e os defeitos preexistentes avaliados pelos agentes hegemônicos - essas "rugosidades", no dizer de Santos (1999) - constituem as coordenadas que orientam as novas ações, as quais estão subordinadas a uma estratégia de conjunto e diretamente relacionadas ao imperativo da competitividade.

De fato, as ações definirão os objetos e lhes darão novos sentidos. Por sua vez, os objetos receberão e valorizarão diferentemente as ações, geografizando-as de modos diversos. Ora, nessa equação, não está revelado somente o hibridismo do espaço, como sugere Santos (1999), mas também, como consequência, a sua diferenciação, responsável pela demarcação das contradições que o torna mecanismo da acumulação capitalista. Considerar que a intencionalidade das ações ou as próprias ações se geografizam de maneira indiferente é concluir que os espaços têm o "mesmo valor de uso e o mesmo valor de troca, valores que não são afetados pelo movimento da história" (SANTOS, 1999, p.70).

Desse modo, não há como entender um arranjo político e econômico bem definido, que se afirme como configuração precisa de acumulação do capital, sem entender a divisão social do trabalho. Consequentemente, não há como entender combinações sociais de diferentes técnicas e trabalhos sem uma diferenciação no espaço, o que implica a composição desigual de lugares e territórios. Assim, "a divisão social do trabalho não 
pode ser explicada sem a explicação da divisão territorial do trabalho, que depende, ela própria, das formas geográficas herdadas" (SANTOS, 1999, p.113).

Cada território, com suas características específicas perante o movimento de acumulação capitalista global, revela uma combinação única tornada mecanismo de reprodução das formas de valorização. Disso depende a integração flexível e toda sorte de ramificações das estratégias em rede, utilizadas por empresas industriais e/ou financeiras.

No âmbito da reestruturação produtiva, por exemplo, as novas possibilidades de controle flexível do processo global de produção industrial surgem, unicamente, em função dos diferentes papeis dos espaços diante da difusão da inovação e da aplicação das normas correspondentes. Simultaneamente a uma nova racionalização dos sistemas produtivos na indústria, ocorre uma instrumentalização espacial, transformada em mecanismo da racionalidade industrial. Entretanto, essa instrumentalização só se afirma se o espaço o permitir, respondendo positivamente às intencionalidades externas com a sistematização convergente das formas e das políticas, o que com certeza não se faz de maneira homogênea.

O resultado é o acirramento das diferenças geográficas e o aprofundamento de recortes verticais no espaço, gerando maior hierarquização dos territórios destinados à facilitação da fluidez produtiva e financeira. A organização espacial que resulta dessa dinâmica será sempre desigual. Os diferentes espaços que montam as bases de uma arquitetura renovada para a globalização reproduzem o princípio da desigualdade como fator essencial da acumulação. $\mathrm{O}$ espaço, nesse sentido, em hipótese alguma organiza de maneira equitativa as escalas sociais e econômicas de desenvolvimento.

De fato, são diferenciações geográficas que se manifestam "nos modos de vida, nos padrões de vida, nos usos dos recursos, nas relações com o ambiente e nas formas políticas e culturais" (HARVEY, 2004, p.110). Falar de acumulação capitalista é, então, falar da produção de diversidades territoriais, seja em configurações anteriores ou configurações recentes, seja em recortes espaciais que agrupam países ou recortes subnacionais/regionais.

Isso coloca o espaço como vetor das transformações sociais, dando-lhe caráter político-econômico concreto, principalmente como instrumento de reprodução global das estratégias de produtividade e rentabilidade. No contexto atual, como não poderia deixar de ser, a nova configuração de acumulação do capitalismo também organiza as ações e os objetos num plano marcado pela diferenciação espacial.

É relevante afirmar, no entanto, que, graças às importantes redefinições no âmbito das normas políticas de desregulamentação e das técnicas informacionais, os agentes hegemônicos da globalização capitalista aproveitam de modo bem mais eficaz a diferenciação do espaço. $\mathrm{O}$ arranjo da desigualdade é explorado de maneira mais aperfeiçoada, pois as empresas integram as diferenças de produtividade do trabalho e as de custo dos capitais a uma ótica mundial (MÉNDEZ, 2018). Nessa nova configuração, os fatores circulam em função das necessidades dos capitais, responsáveis por uma especialização que aprofunda ainda mais as diferenças dos espaços (PECK, THEODORE e BRENNER, 2012). 
Na esfera produtiva, o processo se caracteriza pela transferência de segmentos tradicionais da indústria para espaços em que as condições necessárias de desenvolvimento capitalista não tinham sido plenamente constituídas. Em verdade, a especialização flexível e a desintegração dos obstáculos espaciais proporciona aos investimentos produtivos uma mobilidade sem precedentes na escala mundial, integrando o espaço por meio de uma rede que articula fluxos materiais e imateriais, representados por capitais ávidos por valorização. Como consequência, nas últimas décadas, antigas regiões industrializadas atravessaram importantes modificações ao experimentar declínio industrial acelerado, enquanto outras regiões sem tradição fabril converteram-se em novos centros de crescimento industrial e expansão econômica. Isso pode ser observado nas mudanças apontadas pela Figura 1, que apresenta a percentagem da distribuição da produção industrial nas principais regiões do mundo, demarcadas em 1980 e 2016.

Esse movimento é mais intenso nos países de tradição industrial, bem como naqueles em que a industrialização se desenvolveu no pós-guerra, como mostram Michalet (2003 e 2009) e Mouhoud (2008) em livros que tratam do assunto. Nos Estados Unidos, por exemplo, as mudanças abriram novas fronteiras territoriais, como confirmam os polos industriais do Sul, da Costa Oeste e da região das montanhas. Todavia, a decadência de muitos setores manufatureiros deprimiu áreas industriais tradicionais, embora algumas tenham conseguido se reestruturar, como a região de Boston. Já na Europa, os movimentos de desindustrialização atingem, entre outros, Inglaterra e França, com importantes regiões tradicionais redefinindo seus papeis econômicos industriais, como Manchester-Liverpool e Calais-Dunkerque.

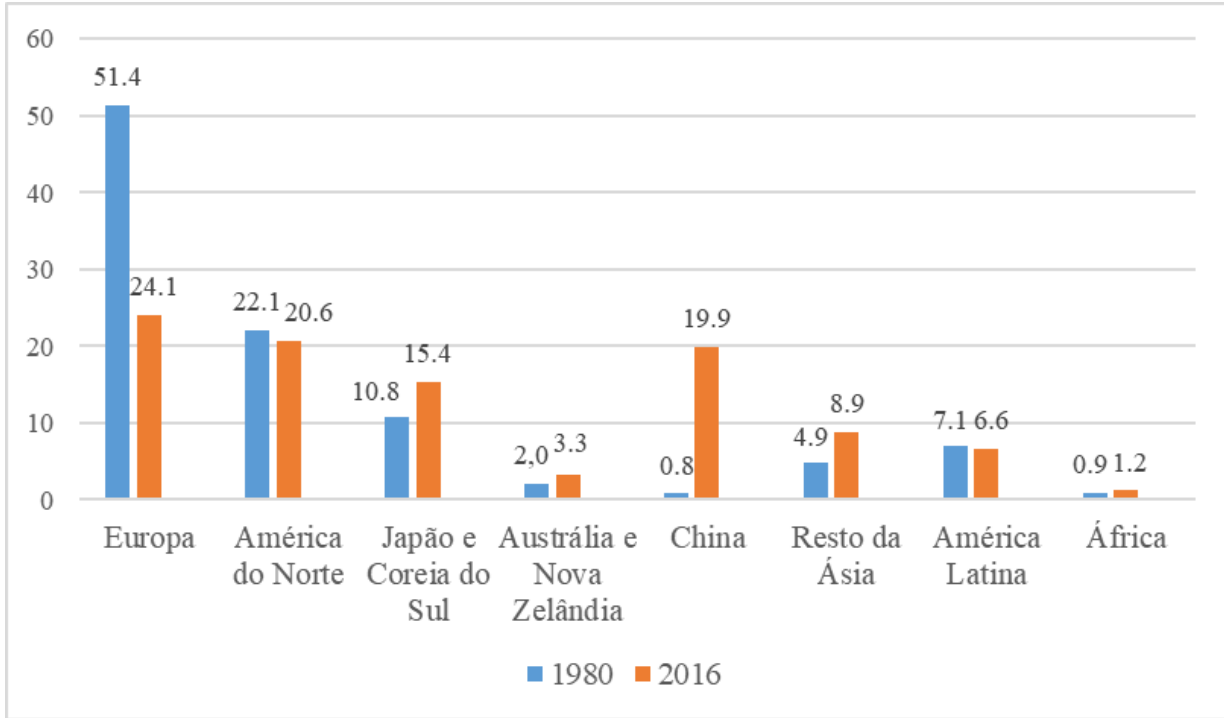

Figura 01: Distribuição regional da produção industrial do mundo (\%) - 1980 e 2016.

Fonte: ONUDI. Iternational Yearbook of Indutrial Statistics. Elaborado a partir de Méndez (2018). 
Ao mesmo tempo, outras regiões ao sul desses países estão ganhando importância, principalmente com atividades de alta tecnologia. Se esse movimento das empresas já podia ser observado no pós-guerra, numa fase de expansão capitalista marcada pelo padrão fordista de verticalização dos circuitos produtivos, agora ele se intensifica no ritmo da flexibilidade que constitui o imperativo da competitividade global.

Como assinala Michalet (2009), as empresas não têm mais tempo de negociar interminavelmente com as administrações públicas dos países ou das regiões anfitriãs a autorização para investir. Quando as decisões demoram demais ou as condições exigidas são altas, elas simplesmente se deslocam, escolhendo espaços em que a oferta de vantagens é maior. Assim, se a "relocalização" (MICHALET, 2009; MOUHOUD, 2008) se constituía em uma estratégia industrial de produtividade apenas para alguns setores da economia há algumas décadas, hoje ela se impõe como mecanismo essencial para a manutenção e/ou a ampliação das taxas médias de acumulação. $\mathrm{Na}$ verdade, a relocalização consiste numa estratégia de reestruturação que aprofunda as modificações implantadas por meio de reengenharias produtivas, mediante o deslocamento de filiais ou de todas as unidades de produção de uma empresa com base nas vantagens técnicas e políticas oferecidas pelos diferentes espaços.

Somente assim se torna possível combinar as concepções gerenciais e espaciais de estratégia, integrando os modelos de flexibilização produtiva e do trabalho ao acesso a novos mercados nacionais e regionais capazes de oferecerem minimização dos custos de produção.

Inserido no processo, o ordenamento desigual do espaço se mostra crescentemente eficaz como mecanismo de acumulação ampliada. É exatamente num contexto como o das últimas décadas, marcado por crescentes quedas nas taxas médias de lucro dos capitalistas, que essas estratégias territoriais são intensamente utilizadas. O espaço, nesse sentido, está no fundamento do movimento sempre renovado de acumulação do capital. A materialização da sua dialética se confirma a partir de um arranjo sistêmico de diferenciação cujo aspecto mais marcante é a simultaneidade das dinâmicas num plano desigual, garantindo a exploração das vantagens com base num esquema integrado de disparidades.

Desse modo, o contexto que articula objetos e ações a partir de uma combinação transescalar que envolve o global, o nacional, o regional e o local coloca em ação o movimento da história a partir da organização e reorganização do espaço. A mais recente configuração da Geografia do capitalismo revela essa tendência com mais clareza do que em qualquer outro momento, e nenhuma leitura dos novos acontecimentos apreenderá a complexidade do processo se prescindir dessa concepção.

\section{Considerações}

As novas relações de reprodução capitalista privilegiam a posição econômica conquistada pelas finanças na ordem da acumulação. Os acontecimentos dos últimos anos revelam que o capital que se valoriza sob a forma de aplicação financeira e que provém 
da repartição do lucro das empresas industriais apresenta-se cada vez mais como fração dominante, inclusive com condição de comandar as outras frações de capital e seus diferentes ritmos de acumulação.

É dessa maneira que o novo mundo industrial se molda à lógica competitiva das finanças, para a qual a rentabilidade a curto prazo e a garantia por liquidez terá sempre um papel hegemônico. Consequentemente, os padrões produtivos mudam como um todo e a atividade industrial, reagindo por mimetismo, toma para si as metas e os ritmos da acumulação com dominação financeira.

São fatores que obrigam os dirigentes empresariais a se adaptarem aos ritmos mais frenéticos da concorrência capitalista, geralmente importando estratégias do universo das finanças ao incorporarem, se não o conteúdo dos mecanismos de acumulação por especulação, as formas de extrair excedentes compatíveis com os objetivos impostos pelos investidores/acionistas, apresentando resultados contábeis igualmente favoráveis.

A nova realidade confirma a tese de Lordon (2008) sobre o poder das finanças, capaz de transformar a "neurose" da liquidez e da alta rentabilidade num paradigma que avança para todas as esferas da economia, cuja consequência não poderia ser outra senão a busca "obsessiva" da reversibilidade e da lucratividade máxima na produção e nas relações de trabalho. Tal reversibilidade se traduz em redução dos direitos trabalhistas, intensificação da jornada de trabalho, implantação de sistemas de produção flexíveis e precarizados, adoção de círculos de controle de qualidade do produto com progressivo aumento das exigências laborais, generalização das formas de subcontratação e outras estratégias que marcam a demanda por altas taxas de acumulação pela via da eficácia da produtividade.

Esses procedimentos são usados com frequência pelas empresas das mais tradicionais regiões industriais do mundo. Isso não significa, contudo, que as novas regiões industriais também não sejam afetadas pelo receituário da reestruturação produtiva. Nesse caso, além da recomposição de quadros inteiros do processo produtivo em zonas capitalistas periféricas de tradição maquinofatureira, novos "lugares de reserva" penetram no circuito da acumulação ampliada do valor, não sem incorporar de imediato as cobranças administrativas e os desenhos produtivos obcecados pela apreensão de superlucros.

Ao observar esse processo, constatamos a importância do espaço geográfico como suporte e condicionante de todas essas mudanças. $\mathrm{O}$ conjunto de intencionalidades econômicas e políticas precedentes à ação só se afirma se constituído num sistema localizado de objetos, que por sua vez se apresenta como uma norma para o exercício de determinados interesses (SANTOS, 1999).

A nova realidade tecnológica e informacional é capaz de integrar, pela via da circulação e da produção, parcelas do espaço geográfico com diferentes preços e produtividades de trabalho, abrindo uma nova possibilidade de redução de custos para os capitalistas. Assim, a diferenciação espacial se manifesta como síntese sempre provisória e renovada das contradições e da dialética social neste novo momento. 
No âmbito de todas essas possibilidades, porém, o espaço não se apresenta apenas como uma ferramenta em prol dos interesses da acumulação. Ele também tende a ser apropriado a partir de fundamentos de libertação do imperativo da financeirização, no contexto de uma transformação econômica e política que proponha mais equidade socioeconômica. O maior desafio que se apresenta para a diferenciação espacial é como pautar a sua capacidade de tecer sinergias em favor de uma plena reestruturação da sociedade, impondo à ordem econômica desigual do presente uma resposta humanamente mais generosa.

\section{Referências}

AUVRAY, T. RABINOVICH, J. Cambios en la estructura de propiedad y la financiarización de las grandes empresas en Francia. In: SCHORR, M.; WAINER, A. (eds.). La financiarización del capital: estrategias de acumulación de las grandes empresas en Argentina, Brasil, Francia y Estados Unidos. 1a ed. - Ciudad Autónoma de Buenos Aires: Futuro Anterior Ediciones, 2018. p. 27 - 48.

BELUZZO, L. G. Prefácio. In: CHESNAIS, F. A finança mundializada: raízes sociais e políticas, configurações, consequências. São Paulo: Boitempo, 2005. p. 07 - 16.

BRENNER, N. Após a neoliberalização. In: BRENNER, Neil. Espaços da urbanização - o urbano a partir da teoria crítica. Rio de Janeiro: Letra Capital, 2018. p. 161 - 194.

CAMAGNI, R. Organisation économique et réseux de villes. In: SALLEZ, A. (Org.). Les villes, lieux d'Europe. Paris: Datar/Éditours de l'Aube, 1993. p. 107 - 128.

CHESNAIS, F. O capital portador de juros: acumulação, internacionalização, efeitos econômicos e políticos. In: CHESNAIS, F. A finança mundializada: raízes sociais e políticas, configurações, consequências. São Paulo: Boitempo, 2005. p. 35 - 68.

DOWBOR, L. A era do capital improdutivo - a nova arquitetura do poder, sob dominação financeira, sequestro da democracia e destruição do planeta. São Paulo: Autonomia Literária, 2017.

HARVEY, D. Condição pós-moderna. 7ª.ed. São Paulo: Edições Loyola, 1998.

HARVEY, D. Espaços de esperança. São Paulo: Edições Loyola, 2004.

LENCIONI, S. Da cidade e sua região à cidade-região. In: SILVA, J. B. da; LIMA, L. C; ELIAS, D. (Orgs.). Panorama da geografia brasileira. São Paulo: Annablume, 2006. v.1. p. $65-76$.

LORDON, F. Jusqu'à quand? Pour em finir avec les crises financières. Paris: Raison d'agir Édition, 2008.

MÉNDEZ, R. La telaraña financeira - uma geografía de la financiarización y su crisis. Santiago: RIL Editores/Insituto de Estudios Urbanos e Territoriales UC, 2018.

MÉNDEZ, R; CARAVACA, I. Organización industrial y território. Madri: Editorial Síntesis, 1996. 
MICHALET, C. O que é mundialização? São Paulo: Edições Loyola, 2003.

MICHALET, C. Mondialisation, la grande rupture. Paris: Éditions La Découvert, 2009.

MOUHOUD, E. M.. Mondialisation et délocalisation des entreprises. Paris: Éditions La Découvert, 2008.

PECK, J.; THEODORE, N.; BRENNER, N. Mal-estar no pós-neoliberalismo.

Novos Estudos CEBRAP, São Paulo, n. 92, p. 59 -78, março. 2012.

PEREIRA, J. M. D. Flexibilização da produção e subcontratação do trabalho: o caso da indústria gaúcha de calçados de couro. 1998. 271 f. Tese (Doutorado em Economia) Universidade Federal de Pernambuco, Recife, 25 de agosto de 1998.

PETRELLA, R. Los limites a la competitividade: cómo se debe gestionar la aldea global. Buenos Aires: Universidad Nacional de Quilmes/Editorial Sudamericana, 1996.

SANTOS, M. A natureza do espaço. 3.ed. São Paulo: Hucitec, 1999.

SASSEN, S. As finanças e suas capacidades: a crise como lógica sistêmica. In:

SASSEN, S. Expulsões - brutalidade e complexidade na economia global. Rio de Janeiro/São Paulo: Paz e Terra, 2016. p. 143-178.

VELTZ, P. Le nouveau monde industriel. Paris: Éditions Gallimard, 2008.

Edilson Pereira Júnior

Professor adjunto da Universidade Estadual do Ceará/UECE/Programa de Pós-Graduação em Geografia/PROPGEO. Bolsista Produtividade CNPq nível 2. Doutor em Geografia pela Universidade Estadual Paulista/UNESP, Campus de Presidente Prudente/SP. Rua Vicente Leite, 2121, Fortaleza-CE. CEP: 60.170.151.

E-mail: edilsonapjr@hotmail.com 